\title{
A distinct imaging phenotype in amyotrophic lateral sclerosis confidently detected on T1 MTC
}

\author{
Antonio Jose da Rocha, Renato Hoffmann Nunes
}

Division of Neuroradiology, Santa Casa de Misericórdia de São Paulo, São Paulo, Brazil

\section{Correspondence to} Dr Renato Hoffmann Nunes, renatohn@hotmail.com

Accepted 12 November 2014

\section{DESCRIPTION}

A 57-year-old woman presented with a progressing asymmetric (left to right) weakness and wasting that spread in the next 3 months from her lower to upper limbs; she exhibited mild hyper-reflexia in all four limbs. No cognitive or sensory impairment was detected. Cerebrospinal fluid and blood analyses were unremarkable. Electromyography showed pathological signs of denervation and chronic reinnervation with spontaneous activity at rest, consistent with a motor neuron disease. The presence of upper motor neuron (UMN) and lower motor neuron (LMN) signs together in multiple regions, on clinical and paraclinical basis, supported amyotrophic lateral sclerosis (ALS) diagnosis, according to current criteria. ${ }^{1}$ An MRI was performed and abnormal corticospinal tract signal intensity was remarkably detected on T1 magnetisation transfer contrast (MTC) images (figure $1 \mathrm{~A}-\mathrm{C}$ ), which supported the presumptive diagnosis of UMN degeneration. The current diagnostic criteria have recently been introduced to better define LMN degeneration; however, paraclinical proof of UMN compromise remains a challenge, particularly in the early stages of the disease. In searching for UMN biomarkers, some conventional and non-conventional MRI techniques have emerged in routine clinical practice to demonstrate UMN degeneration in ALS. ${ }^{1}$

While proton density-weighted imaging (figure $2 \mathrm{~A}-\mathrm{C}$ ) has only moderate sensitivity for ALS diagnosis, a newer MTC technique based on the exchange between stationary (macromolecules) and mobile protons (free water) has been elucidated to highlight structural abnormalities not detected on conventional techniques. ${ }^{2}$ T1 MTC is better able to demonstrate the hyperintensity of the corticospinal tracts in a particular phenotype of imaging in early disease with UMN involvement. ${ }^{23}$
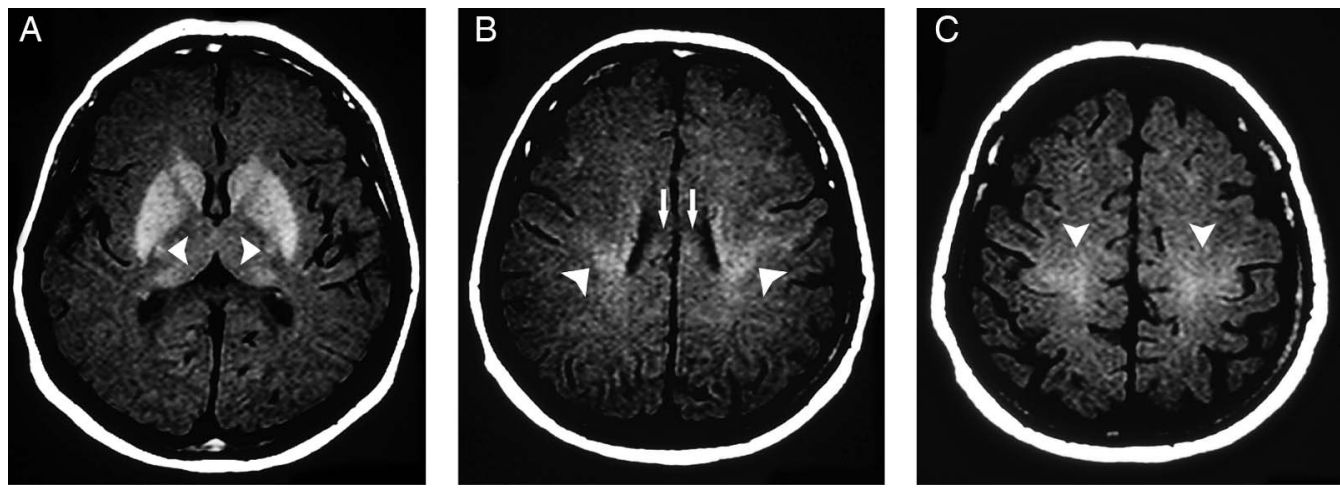

Figure 1 Axial T1 magnetisation transfer contrast (MTC; A-C). Selective hyperintensity (arrowheads) throughout the corticospinal tracts is depicted on T1 MTC axial images, assuming a typical 'W-like appearance' crossing the corpus callosum (arrows).
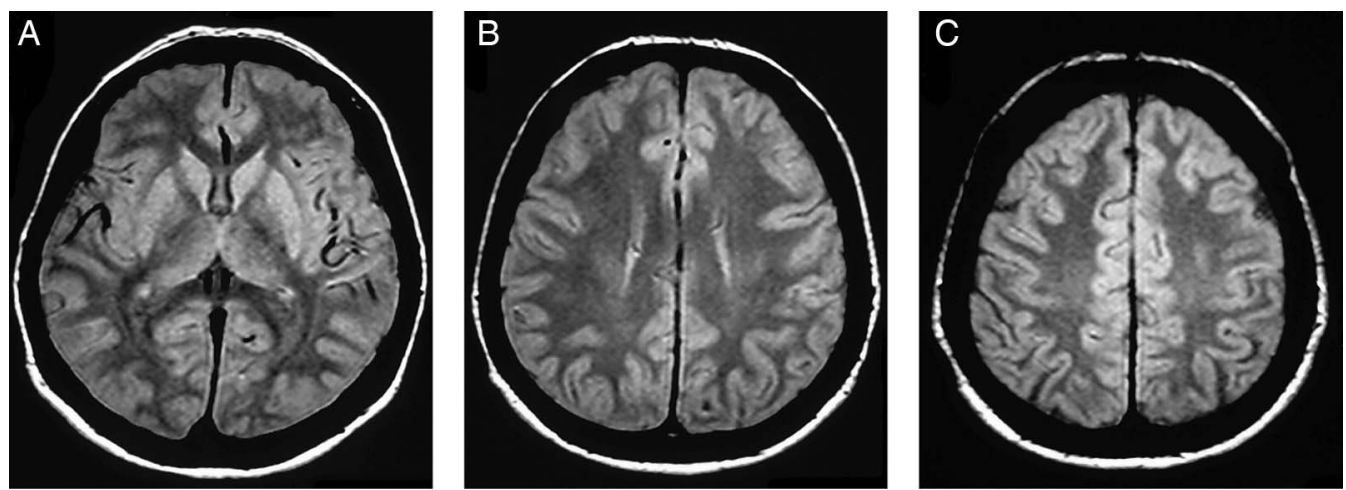

Figure 2 Axial proton density-weighted imaging (PDWl; A-C). PDWI only revealed a faint hyperintensity in the same regions, making the diagnosis more difficult. 


\section{Learning points}

- The early diagnosis of amyotrophic lateral sclerosis might be a challenge; MRI has a potential role as a paraclinical tool for prompt detection of UMN involvement.

- In this case, the MRI signal intensity was useful for detecting upper motor neuron degeneration based on corticospinal tract signal intensity, reinforcing the relevance of the T1 magnetisation transfer contrast (MTC) to demonstrate corticospinal tract degeneration and corroborate an amyotrophic lateral sclerosis diagnosis in a single patient.

- Selective hyperintensity throughout the corticospinal tracts is depicted on T1 MTC axial images, assuming a typical 'W-like appearance' crossing the corpus callosum.
Contributors AJR and RHN were responsible for the study concept, drafting the manuscript, and for acquisition and interpretation of data.

Competing interests None.

Patient consent Obtained.

Provenance and peer review Not commissioned; externally peer reviewed.

\section{REFERENCES}

1 de Carvalho M, Dengler R, Eisen A, et al. Electrodiagnostic criteria for diagnosis of ALS. Clin Neurophysiol 2008;119:497-503.

2 da Rocha A J, Oliveira A S, Fonseca R B, et al. Detection of corticospinal tract compromise in amyotrophic lateral sclerosis with brain MR imaging: relevance of theT1-weighted spin-echo magnetization transfer contrast sequence. AJNR Am J Neuroradiol 2004;25:1509-15.

3 Carrara G, Carapelli C, Venturi F, et al. A distinct MR imaging phenotype in amyotrophic lateral sclerosis: correlation between T1 magnetization transfer contrast hyperintensity along the corticospinal tract and diffusion tensor imaging analysis. AJNR Am J Neuroradiol 2012;33:733-9.

Copyright 2014 BMJ Publishing Group. All rights reserved. For permission to reuse any of this content visit http://group.bmi.com/group/rights-licensing/permissions.

BMJ Case Report Fellows may re-use this article for personal use and teaching without any further permission.

Become a Fellow of BMJ Case Reports today and you can:

- Submit as many cases as you like

- Enjoy fast sympathetic peer review and rapid publication of accepted articles

- Access all the published articles

- Re-use any of the published material for personal use and teaching without further permission

For information on Institutional Fellowships contact consortiasales@bmjgroup.com

Visit casereports.bmj.com for more articles like this and to become a Fellow 